\title{
A New Offer of Approach of Motivation Factors Measurement
}

\author{
Nargiz E. Samadova1, Rustam B. Rustamov ${ }^{2}$ \\ ${ }^{1}$ ENCOTEC Ltd., Baku, Azerbaijan \\ ${ }^{2}$ Laboratory of Modern Method of Applied Electrodynamics, Institute of Physics, Azerbaijan National Academy \\ of Science, Baku, Azerbaijan \\ Email: nargiz_e samadova@yahoo.com, r_rustamov@hotmail.com
}

Received 29 May 2015; accepted 14 June 2015; published 19 June 2015

Copyright (C) 2015 by authors and OALib.

This work is licensed under the Creative Commons Attribution International License (CC BY). http://creativecommons.org/licenses/by/4.0/

(c) (i) Open Access

\section{Abstract}

The fact is that it is always attempted to develop suitable motivation factors satisfying company management needs in this very sensitive as well as vital aspects of development. Each of existing approaches at some point has been applied and tested as to its effects on people's lives, jobs, and personal goals in life as well as in the work place. Honestly, it is very difficult to find out motivation factors, which can be used in wide areas of management process. There is no flexible manner of factors to apply in large areas of business. It makes necessary to adopt behavior of motivation factors depending on business type or spheres. Obviously it opens an environment to differentiate motivation factors for successful observation and monitoring of the process. There are wide methods of motivation factors existing in different sources [1]. This paper offers a new approach of definition of motivation factors. For this reason a cognitive classification formed on the Masloff hierarchy categories is suggested. It states detailed classification of a large number of factors, which make assume a wide use of such option in different type of business areas. One more advantage of this classification of motivation factors is the most convenient of measurability of developed system. This subject is highly important especially meeting the main requirements of the system with SMART segmentation. It makes possible and opens an opportunity easily to assess the system for further right decision-making.

\section{Keywords}

Motivation, Factor Measurement, Hierarchy, Indicator, Evaluation, Determination, Employee, Performance, Self-Actualization, Esteem

Subject Areas: Dynamical System, Fluid Mechanics

\section{Introduction}

Motivation consists a psychological aspect of human perception, which makes of object of inquires of scientist 
as one of the important options in management process. Because motivation is a psychological construct and human condition that cannot be observed or recorded directly. It is vital to study aspect of motivation and get an answer to the important question - how to measure motivation, and what kind of criteria is required to be undertaken within motivation factors measurement. In some cases, approach of measurement of motivation was stated in terms of observable cognitive (sense, perception, spirit, aspiration), affective (background, experience), behavioral (presentably, performance) and physiological (emotion, brain activation) responses and using self-reports [2]. It can be launched of conception of comparative analysis of selected factors which we are intending to measure. It is highly important definition, segmentation and differentiation of accepted items and availability of those items merging into the SMART system.

There is no doubt that above indication makes an important determination what type of motivation we are expecting to capture and shows how to measure motivation. Undoubtedly, it is the fact of clear understanding of achieved results.

The success depends on the philosophy and way of indicators of the factors of motivation selected for measurement. It is the first step of approach in the process definition. The next important option is method or module use as an instrument for measurement of motivation factors.

\section{Distinguish Approach of Motivation Definition and Its Existing Methods of Measurement}

The fact is that motivation factor can be reflected by distinguishing between different dimensions of motivation factors for instance, speed of commitments of employee during task implementation in working place. The other factor of motivation can be stated relation of individual orientation to the nominated goals, which is the picture of number of factors motivating of a person on his/her future expectations. It opens an environment to find out indicators how to measure of motivation factors depend of those achievements [3]-[5].

There is one more undertaking in motivation factors definition trended to the study of human behavior. It considers selection appropriate criteria developments, which can be used and applied for measurement of motivation. In some cases, this philosophy is integrating to the goals as an inherent part of motivation. Such kind of integrated motivation factor is comparatively easily can be measured since contains almost two indicators which creates positive environment in measurement stage of definition. Undoubtedly, goal does not limit only one option. There are a large of options consisting such segments like choice, speed and performance forming the human behavior. Separately each of those options can be participate in achievement of nominated target. Undoubtedly, those options can also be presented by sections. For example, it can be segmented into accuracy, amount of done job, quality etc. This option tangible helps to reflect the form and approach of measure of motivation factors. As it sees from above indications, it is enough good characterizer's human performance.

\subsection{Differentiation of Motivation Scale Frame}

The fact is that different targets or aims could be faced during task executions. For instances, defined target can reflected between accuracy and task execution speed. In this pursuit with approach of selection of motivation segments creates possibility to achieve of targets for measurement.

Why it has been identified as the cognitive source in measurement process? It can be stated that accuracy and speed are measurable parameters. An accuracy of task solving seems not directly would be assessed. There is number of methods make available to evaluate of quality of performance within task execution. At the same time relations between accuracy and speed can play a good indicator of motivation of human behavior [6].

It has to be considered that when performing many skills, the accuracy of an action will influence the speed of the action such that accuracy motivation will reduce speed, whereas motivation to be quick will reduce accuracy.

\subsection{Ability and Capacity as the Motivation}

In some cases the measurement can be captured fluctuation of motivation do not related to the studied process. It makes necessary and important an increase number of motivation factors or factors consisting internally number of segments. For instance, ability and capacity are a forming such a type of approach in motivation measurement. A contains of ability and capabilities are following: 
- education;

- experience;

- jobs types of involvement and responsibilities within done jobs;

- skills;

- any others.

Therefore, big number of segments makes sure of increasing of accuracy of measurement process of motivation factors.

\subsection{Learning Desire}

Learning is the process having significant influence on performance. There is no doubt that there is a link between learning desire and skills, ability of engagement of complicated problem solving, personal improvement opportunities etc. In conformity with pursuit and perception of personal habit a learning is one more factor of motivation showing the way of measurement of organization motivation as an significant element of organization management process [7].

\section{Conceptual Model of Motivation Factor Measurement}

There is statement of the conceptual approach for measurement of the motivation factors includes the interrelationships between employee efforts, employee performance, stakeholders for definition of the motivational level of individuals. It is very important issue in organization management, particularly for the companies based on learning organization philosophy in its development process.

In general, it concerns following of definitions:

- employee performance and its measurement and evaluation;

- compensation condition both fixed and variable;

- carrier promotion.

Taking into consideration above indications it has been offered model of approach how to achieve expectations in motivation factor measurement. For this reason suggested to classify of motivation factors by categories based on Masloff hierarchy [8]. It runs and consists mainly self actualization, esteem, love/belonging, safetysecurity, physiological classification based on which can be developed further actions of motivation clarification options. It is necessary to indicate that each of classification has an own sub-items, which can be reflected as below:

\section{- Self actualization}

$\checkmark$ morality;

$\checkmark$ creativity;

$\checkmark$ spontaneity;

$\checkmark$ problem solving;

$\checkmark$ lack of prejudice;

$\checkmark$ acceptance of fact;

$\checkmark$ talent creativity fulfillment.

- Esteem

$\checkmark$ self-esteem;

$\checkmark$ confidence;

$\checkmark$ achievement;

$\checkmark$ respect of others;

$\checkmark$ respect by others;

$\checkmark$ mastery recognition respect.

- Love/belonging

$\checkmark$ friendship;

$\checkmark$ family.

- Safety-security

$\checkmark$ body;

$\checkmark$ employment;

$\checkmark$ resources; 
morality;

$\checkmark$ the family;

$\checkmark$ health;

$\checkmark$ property.

- Physiological

$\checkmark$ breathing;

$\checkmark$ foot;

$\checkmark$ water;

$\checkmark$ sleep;

$\checkmark$ shelter;

$\checkmark$ warms.

\section{Data Collection Method}

The appropriate method selection for data collection is one of the significant aspect of motivation measurement process. In our case, data was collected at a single research site in the selected private local company. This approach made possible to undertake specifics of local behavior, culture and other characteristic features of people consisting mainly in Masloff's hierarchy.

Table 1 shows classification and sub-items of classification Form of questionnaire developed for data collection. For this reason, it has been conducted tests for collection of personnel data and conducted a survey amongst all individual employees of the company. Before setting up and sending out the survey it was conducted number of interviews with different organization positional status level of employees in order to understand of the organization, the activities performed and the incentive systems in place during evaluation process. The personnel data consists of information indicated in the Table 1 created on the base of Masloff's hierarchy.

\section{Motivation Factor Measurement}

In order to grasp the status and place of motivation in the organization of employees, the respondents were asked to react to the statements developed within the questionnaire. Five statements were intended to measure and

Table 1. Masloff hierarchy categories bases motivation factors classification.

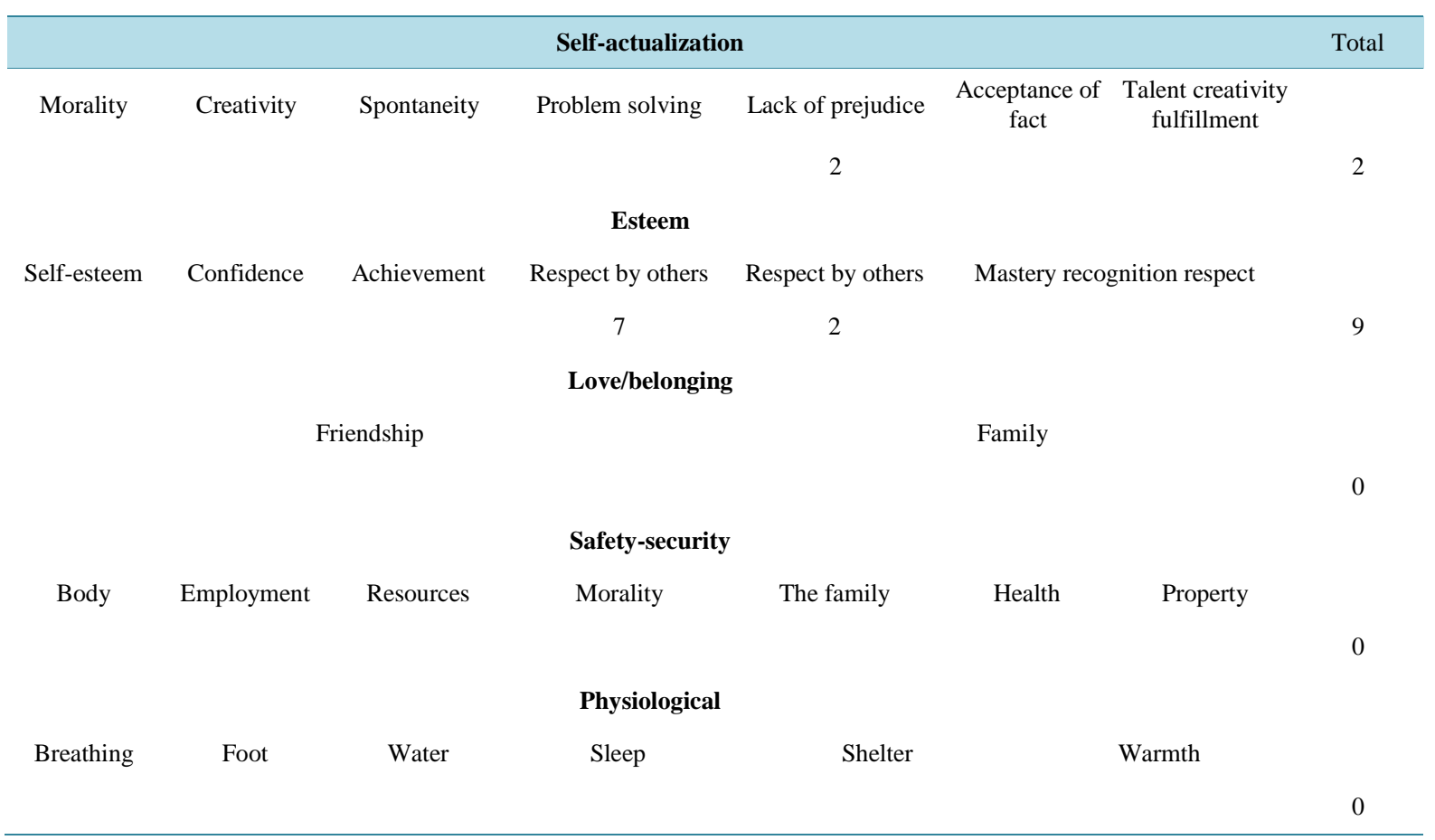


estimate for definition of the level of organizations intrinsic motivation. Motivation factor analysis was used to identify the dimensions of the responses. Each factors have been segmented into the sub-items which significantly impacted to achieve high accuracy of results within calculation stage of motivation measurement process.

In the other hand categories of Masloff's hierarchy were classified by coefficient of significance of attitude. For instance physiological category was assess as coefficient 0.2 and self-actualization as 1.0.

Table 2 has developed base on questionnaire results conducted among organization staff and demonstrates category positions and coefficients $(\mathrm{k})$ consequently depends of their status of importance. It has been use below formula for motivation factor (MF) calculation:

$$
\mathrm{MF}=\text { Total } \times \mathrm{k}
$$

where "Total" relates to the Masloff hierarchy categories based on the data collected by questionnaire (Table 1 , column "Total").

It has been calculated and graphed of motivation factors on Masloff's hierarchy categories. Figure 1 shows results of measurement of motivation factors. A motivation square "MS" gives definition of the location and place of condition of organization motivation. Position of "MS" can change depends of qualitative characteristics of Masloff's hierarchy categories. The best characteristic of Masloff's hierarchy categories are in the area to close to self-actualization as it has approached by Masloff's hierarchy philosophy. A shifting to the left direction of MS is the indication and reflection of the staff low motivation factor.

In the meantime half-width of MS is also very important parameter and indicator of motivation factor. Because, the half-width demonstrates the degree of blurriness of the motivation factor. The blurriness of MS takes the best point in the case of lower half-width, which makes easily to assess the condition of motivation factor of staff. It is an excellent instrument for managers during management process of company motivation.

\section{Conclusions}

In this paper, an employee motivation and motivation categories for the level of motivation are discussed. The problem of motivation is important from the point of view of categories definition of motivation. It is required to state appropriate elements of motivation in order to be able to evaluate of motivation factors.

This paper shows a new approach of the motivation classification based on Masloff's hierarchy categories. It makes possible to select factors consisting of motivation factors with further implementation of evaluation stage. This is demonstrating suitability of motivation measurement as a significant object of organization management process.

An essential place in this investigation takes visual presentation of outcomes of measurement. Performance of the motivation factors with integration of the method of measurement opens a picture for managers how and

Table 2. Masloff hierarchy categories and coefficient of importance with results of questionnaire.

\begin{tabular}{ccccc}
\hline Physiological $(\mathrm{k}=0.2)$ & Safety-security $(\mathrm{k}=0.4)$ & Love belonging $(\mathrm{k}=0.6)$ & Esteem $(\mathrm{k}=0.8)$ & Self-actualization $(\mathrm{k}=1.0)$ \\
\hline 0 & 0 & 0 & 7.2 & 2 \\
\hline
\end{tabular}

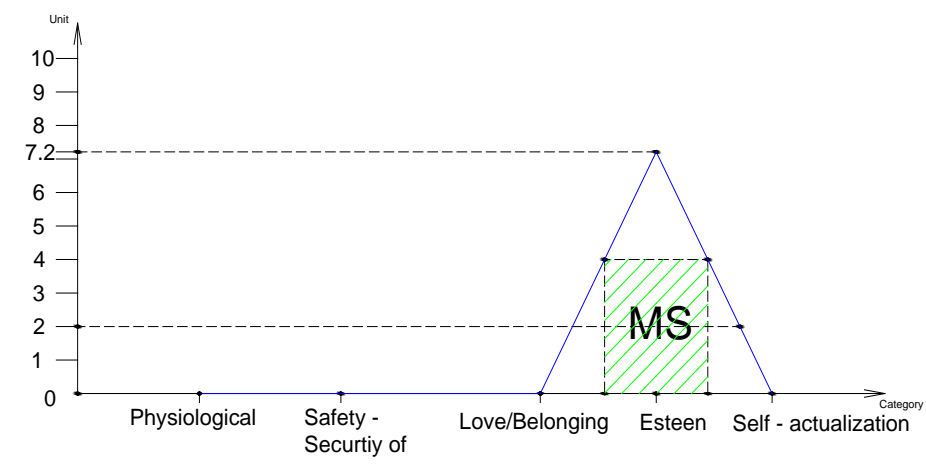

Figure 1. Masloff's hierarchy categories organization motivation factor characteristic. 
what should done for management of the process of employee motivation to orient in the right way of expectation in this vital aspect of organization management.

\section{References}

[1] Ruthankoon, R. and Ogunlana, S.O. (2003) Testing Herzberg's Two-Factor Theory in the Thai Construction Industry. Engineering, Construction and Architectural Management, 10, 333-342. http://dx.doi.org/10.1108/09699980310502946

[2] Touré-Tillery, M. and Fishbach, A. (2014) How to Measure Motivation: A Guide for the Experimental Social Psychologist. Social and Personality Psychology Compass, 8, 328-341. http://dx.doi.org/10.1111/spc3.12110

[3] Ferguson, M.J. and Bargh, J.A. (2004) How Social Perception Automatically Influences Behavior. Trends in Cognitive Sciences, 8, 33-39. http://dx.doi.org/10.1016/j.tics.2003.11.004

[4] Finkel, E.J., DeWall, C.N., Slotter, E.B., Oaten, M. and Foshee, V.A. (2009) Liking Is for Doing: The Effects of Goal Pursuit on Automatic Evaluation. Journal of Personality and Social Psychology, 87, 557-572.

[5] Fishbach, A. and Choi, J. (2012) Self-Regulatory Failure and Intimate Partner Violence Perpetration. Journal of Personality and Social Psychology, 97, 483-499.

[6] Molden, D.C., Hui, C.M., Scholer, A.A., Meier, B.P., Noreen, E.E., D’Agostino, P.R. and Martin, V. (2012) Motivational versus Metabolic Effects of Carbohydrates on Self-Control. Psychological Science, 23, 1137-1144. http://dx.doi.org/10.1177/0956797612439069

[7] Magill, R.A. (2011) Motor Learning and Control: Concepts and Applications. McGraw-Hill, New York.

[8] Maslow, A.H. (1987) Motivation and Personality. In: Frager, R., Fadiman, J., McReynolds, C. and Cox, R., Eds., 3rd Edition, Addison Wesley, Boston. 